\title{
No-reflow phenomenon in the cerebral circulation of the gerbil
}

\author{
M. J. G. HARRISON, L. SEDAL, J. ARNOLD, AND R. W. ROSS RUSSELL \\ From the Department of Neurological Studies, The Middlesex Hospital, and the National Hospital, Queen \\ Square, London
}

SYNOPSIS The no-reflow phenomenon has been produced in the cerebral hemispheres of the gerbil by 30 minutes of bilateral carotid artery occlusion. The no-reflow phenomenon was found to develop in relation to the fall in blood pressure which occurred on release of bilateral carotid clips. Metaraminol tartrate intravenously prevented the fall of blood pressure and significantly reduced the occurrence of the no-reflow phenomenon. Metaraminol tartrate, however, did not alter the morbidity or mortality of carotid artery occlusion for 30 minutes. There is thus no support from these experiments for the view that the no-reflow phenomenon plays an important functional role in the reversibility of the effects of severe cerebral ischaemia.

Ames suggested that a vascular factor might underly the inability of the brain to survive periods of total ischaemia (Cantu et al., 1969). He found that after five minutes of complete interruption of the cerebral circulation in the rabbit, reperfusion of the capillary bed was patchy. Regions failed to fill with a carbon black suspension (Cantu and Ames, 1969), and this incompleteness of microvascular filling after ischaemia has been called the 'no-reflow' phenomenon. Crowell and Olsson (1973) demonstrated that a similar defect of microvascular filling may follow temporary regional ischaemia in the monkey brain. In the cat, the no-reflow phenomenon was detected after eight minutes of total cerebral ischaemia but washing through the cerebral hemispheres with saline during the period of ischaemia prevented the development of this phenomenon (Olsson and Hossmann, 1971); in these animals the EEG and pyramidal response recovered more rapidly (Hossmann and Olsson, 1970).

The present experiments were designed to study further the functional significance of the no-reflow phenomenon in the cerebral circulation. Previous studies have employed intracardiac or aortic injections of a carbon suspen-

(Accepted 8 July 1975.) sion from a reservoir. A more physiological $\stackrel{0}{0} \overrightarrow{\frac{\vec{P}}{0}}$ approach has been adopted in the present experi- $\stackrel{\rho}{\stackrel{9}{\circ}}$ 음 ments by employing intravenous infusion of an $\stackrel{\mathbb{Q}}{-}$ isotonic carbon suspension.

\section{METHODS}

Severe ischaemia of the cerebral hemispheres was produced in adult Mongolian gerbils (Meriones unguiculatus) by bilateral clipping of the common carotid arteries in the mid-cervical region through a midline incision under pentobarbitone anaesthesia $(5 \mathrm{mg} / \mathrm{kg}$ intraperitoneally). In some animals, arterial blood pressure was monitored by an intra-arterial cannula inserted in the femoral artery. At the end of a 30 minute period of occlusion of both carotid vessels, the clips were removed. Some animals were allowed to recover and were observed for signs of neurological damage and the morbidity and mortality of the procedure was assessed. In others, 10 minutes after release of the clips, $1.0 \mathrm{ml}$ of a carbon suspension (isotonic 'biological' india ink, Pelikanwerke) was injected into a femoral vein. The animal was then killed by decapitation and the brain removed. One millimetre sections of the formol-fixed brain were cleared in oil of wintergreen and viewed under a dissecting microscope. Any regions of the brain that did not show a normal capillary meshwork filled with carbon suspension were noted as regions of noreflow.

In further groups of animals, a single injection of 
$2.0 \mu \mathrm{g}$ metaraminol tartrate (Aramine, Merck, Sharp, and Dohme), was given either intramuscularly 7.5 minutes before the end of the period of carotid occlusion or intravenously immediately before release of the carotid clips in order to prevent postligation hypotension.

\section{RESULTS}

MORTALITY AFTER TEMPORARY BILATERAL CAROTID OCCLUSION In 10 animals, both carotid arteries in the neck were clipped for 30 minutes. Six died in the first eight hours after release of the clips. Of the four survivors, two showed abnormal circling movements and died later. The overall mortality was thus eight out of 10 .

THE NO-REFLOW PHENOMENON Areas of no reflow were found in 10 of the 18 brains $(55 \%)$ perfused with india ink 10 minutes after the end of 30 minutes' carotid clipping. Arterial blood pressure was monitored in nine of these animals. The pressure rose during the period of clipping in all animals. In seven, the removal of the clips occasioned an abrupt fall in the blood pressure and the no-reflow phenomenon was present in five of these seven animals. The two animals which had no such drop in pressure during the 10 minutes of restored circulation showed complete capillary filling with the carbon suspension.

In 11 animals, $2.0 \mu \mathrm{g}$ metaraminol tartrate was given intramuscularly after 22.5 minutes of clipping. At 30 minutes the clips were removed, and 10 minutes later india ink perfusion showed the no-reflow phenomenon in only two cases. In 10 of these animals the blood pressure was monitored. The metaraminol tartrate prevented a fall in the mean arterial blood pressure during the period of restored circulation in seven. Of the three animals showing an abrupt drop, two showed regions of no reflow. None of the brains from the seven animals with a maintained level of blood pressure showed the no-reflow phenomenon.

Ten animals were given $2.0 \mu \mathrm{g}$ metaraminol tartrate intravenously immediately before release of the carotid clips. Blood pressure was monitored in all. In none was an acute fall of blood pressure seen at the moment of restoration of the cerebral circulation. In one of these animals two small regions of capillary non-filling were detected.
TABLE 1

RELATIONSHIP BETWEEN NO-REFLOW PHENOMENON AND HYPOTENSION



Thus, in 29 animals in which the blood pressure was monitored, the blood pressure fell abruptly after release of the clips in 10 . Seven of these showed regions of no reflow. In 19 animals the pressure did not fall acutely and in only one of these was the no-reflow phenomenon seen $\left(\chi^{2}=10.7, \mathrm{P}<0.01\right)$ (Table 1). The intravenous injection of metaraminol tartrate immediately before the release of clips reduced the number of animals showing a fall in blood pressure $\left(\chi^{2}=\right.$ $9.2, \mathrm{P}<0.01)$ and reduced the proportion showing the no-reflow phenomenon $\left(\chi^{2}=3.8, \mathrm{P}=0.05\right)$ (Table 2).

TABLE 2

EFFECT OF METARAMINOL TARTRATE ON NO-REFLOW PHENOMENON, POST-ISCHAEMIC HYPOTENSION AND MORTALITY AFTER TRANSIENT BILATERAL CAROTID OCCLUSION

\begin{tabular}{|c|c|c|c|c|c|c|}
\hline & \multicolumn{2}{|c|}{ Mortality } & \multicolumn{2}{|c|}{ No re-flow } & \multicolumn{2}{|c|}{$\begin{array}{c}\text { Blood } \\
\text { pressure } \\
\text { fall }\end{array}$} \\
\hline & (no.) & $(\%)$ & (no.) & $(\%)$ & (no.) & $(\%)$ \\
\hline $\begin{array}{l}\text { No met. tartrate } \\
\text { Met. tartiate* }\end{array}$ & $\begin{array}{l}8 / 10 \\
9 / 10\end{array}$ & $\begin{array}{l}80 \\
90\end{array}$ & $\begin{array}{r}10 / 18 \\
1 / 10\end{array}$ & $\begin{array}{l}55 \\
10\end{array}$ & $\begin{array}{l}7 / 10 \\
0 / 10\end{array}$ & 70 \\
\hline $\begin{array}{l}\chi^{2} \\
\mathbf{P}\end{array}$ & I & & \multicolumn{2}{|c|}{$\begin{array}{l}3.84 \\
0.05\end{array}$} & \multicolumn{2}{|c|}{$\begin{array}{c}7.9 \\
<0.01\end{array}$} \\
\hline
\end{tabular}

* Metaraminol tartrate intravenously at end of 30 minute period of $2.0 \mu \mathrm{g}$ ischaemia.

EFFECT OF METARAMINOL TARTRATE ON MORTALITY In another nine animals, $2.0 \mu \mathrm{g}$ metaraminol tartrate was given at 22.5 minutes. Clips were removed at 30 minutes. Eight of the nine animals died. Of 10 animals given $2.0 \mu \mathrm{g}$ metaraminol tartrate intravenously immediately before re- 
moval of the clip, nine died. The overall mortality after 30 minutes of bilateral carotid occlusion $(89 \%)$ was thus uninfluenced by metaraminol tartrate despite its effect on blood pressure and on the no-reflow phenomenon (Table 2).

\section{DISCUSSION}

The no-reflow phenomenon has been demonstrated in a variety of organs since Ames's original studies in the rabbit brain (Cantu and Ames, 1969). Several factors appear to be involved in its development. Firstly, the duration of ischaemia is important. Ischaemia of less than about five minutes produces no evidence of impaired capillary reperfusion. Secondly, with prolonged restoration of the circulation the regions of no reflow diminish and the whole change proves reversible (Cantu et al., 1969).

The presence of red blood cells is also critical. Saline wash out of the capillary bed during ischaemia prevents the development of the noreflow phenomenon (Olsson and Hossmann, 1971), and in the rabbit the no reflow is reduced in extent if the haematocrit is reduced (Fischer and Ames, 1972). The area of non-filling in the post-ischaemic renal bed is greater if the perfusate contains calcium treated red cells, which are more resistant to deformation (Summers and Jamison, 1971).

Post-ischaemic hypotension was thought to play a role by Ames et al. (1968), and was shown to be important by Klatzo et al. (1974) using temporary clipping of one carotid artery in the gerbil. The present study extends these observations and confirms the highly important role of a period of low perfusion pressure in the immediate post-ischaemic period, in provoking the noreflow phenomenon.

The picture that emerges from these studies, and others in other tissues (Fischer, 1973), is of trapping of red blood cells if perfusion be at low pressure, in a vascular bed damaged by ischaemia. Ischaemic cells swell due to failure of metabolic ion pumps (Leaf, 1970) and endothelial cell swelling and bleb formation (Chiang et al., 1968) may compromise the lumen of small capillaries. Red blood cells retained in the ischaemic tissue during the period of arrested flow may also suffer ischaemic damage and become less mechanically deformable. This effect, together with increased viscosity (Merrill, 1969), may increase the risk of cell trapping in capillary channels whose lumen has become irregular due to bleb formation.

The no-reflow phenomenon can be avoided by the prevention of ischaemic cell swelling by the infusion of hypertonic solutions during ischaemia (Cantu and Ames, 1969), by reduction of the haematocrit of the blood during the period of restored circulation (Fischer and Ames, 1972), or by preventing post-ischaemic hypotension (Klatzo et al., 1974; present study).

Hossmann and Olsson (1970) showed that eight minutes of total ischaemia of the cat brain caused the no-reflow phemonenon demonstrable by a carbon suspension 20 minutes later. Saline perfusion of the brain during ischaemia prevented the development of the no-reflow phenomenon and the EEG and pyramidal responses returned more rapidly and more completely. These experiments might be taken to support Ames's original view that a vascular factor influenced the vulnerability of the brain to ischaemia and was an important factor in the impaired recovery from all but very brief periods of ischaemia. Ginsberg and Myers (1972) similarly felt that the no-reflow phenomenon contributed to the neuropathology of cerebral circulatory arrest.

The present experiments, on the other hand, show that the prevention of the no-reflow phenomenon in the gerbil brain (by preventing postischaemic hypotension) has no effect on the animal's ability to survive. It seems possible, therefore, that the beneficial effect of saline perfusion in Hossmann and Olsson's experiments was due to the prevention of the accumulation of metabolites rather than to the avoidance of the no-reflow phenomenon.

The idea that the no-reflow phenomenon might contribute to the neuropathology of ischaemia has also been challenged on different grounds by Brierley (1973) who has pointed out that it fails to explain the selective vulnerability of certain cells. Purkinje cells and neurones of the third and fifth layers of the cortex for example are particularly vulnerable during severe ischaemia of the brain. Eadie et al. (1971) have presented evidence that such differences in cell vulnerability may be related to the volume or volume/area ratios of cells, as reflected in their content of oxidative enzymes. 
There is thus no evidence that the no-reflow phenomenon plays an important part in the recovery of neuronal function after cerebral ischaemia in the gerbil.

\section{REFERENCES}

Ames, A., Wright, R. L., Kowada, M., Thurston, J. M., and Majno, G. (1968). Cerebral ischemia. 2. The no-reflow phenomenon. American Journal of Pathology, 52, 437-453. Brierley, J. (1973). Cited in Fischer, E. G. (1973).

Cantu, R. C., and Ames, A. (1969). Experimental prevention of cerebral vasculature obstruction produced by ischemia. Journal of Neurosurgery, 30, 50-54.

Cantu, R. C., Ames, A., Dixon, J., and Digiacinto, G. (1969). Reversibility of experimental cerebrovascular obstruction induced by complete ischemia. Journal of Neurosurgery, 31, 429-431.

Chiang, J., Kowada, M., Ames, A., Wright, R. L., and Magno, G. (1968). Cerebral ischemia 3. Vascular changes. American Journal of Pathology, 52, 455-476.

Crowell, R. M., and Olsson, Y. (1973). Observations on the microvasculature in focal cerebral ischemia and infarction. In 8th Princeton Symposium. Cerebral Vascular Diseases, pp. 77-88. Edited by F. H. McDowell and R. W. Brennan. Grune and Stratton: New York.

Eadie, M. J., Tyrer, J. M., and Kukums, J. R. (1971). Selective vulnerability to ischaemia: Studies in quanti- tative enzyme cytochemistry of single neurons and neuropil. Brain, 94, 647-660.

Fischer, E. G. (1973). Impaired perfusion following cerebrovascular stasis. Archives of Neurology, 29, 361-364.

Fischer, E. G., and Ames, A. (1972). Studies on mechanisms of impairment of cerebral circulation following ischemia: Effect of hemodilution and perfusion pressure. Stroke, 3, 538-542.

Ginsberg, M. D., and Myers, R. E. (1972). The topography of impaired microvascular perfusion in the primate brain following total circulatory arrest. Neurology (Minneap.), 22, 998-1011.

Hossmann, K. A., and Olsson, Y. (1970). Suppression and recovery of neuronal function in transient cerebral ischemia Brain Research, 22, 313-325.

Klatzo, I., Ito, U., Go, G., and Spatz, M. (1974). Observations on experimental cerebral ischaemia in Mongolian gerbils. In Pathology of Cerebral Microcirculation, pp. 338341. Edited by J. Cervos-Navarro. de Gruyter: Berlin.

Leaf, A. (1970). Regulation of an intracellular fluid volume and disease. American Journal of Medicine, 49, 291-295.

Merrill, E. W. (1969). Rheology of blood. Physiological Reviews, 49, 863-888.

Olsson, Y., and Hossmann, K. A. (1971). The effect of intravascular saline perfusion on the sequelae of transient cerebral ischaemia. Acta Neuropathologia, 17, 68-79.

Summers, W. K., and Jamison, R. L. (1971). The no re-flow phenomenon in renal ischemia. Laboratory Investigation, 25, 635-643. 